\title{
Educação financeira: Aposentadoria sob a ótica dos acadêmicos de uma universidade pública do centro oeste de Minas Gerais
}

Financial education: Retirement from the perspective of academics from a public university in the central west of Minas Gerais

Educación financiera: la jubilación desde la perspectiva de los académicos de una universidad pública del centro oeste de Minas Gerais

Recebido: 01/01/2021 | Revisado: 03/01/2021 | Aceito: 05/01/2021 | Publicado: 07/01/2021

Luana Carolina Reis

ORCID: https://orcid.org/0000-0003-4541-0911 Universidade do Estado de Minas Gerais, Brasil E-mail: karolyny0018@gmail.com

Milca Oliveira Borgis

ORCID: https://orcid.org/0000-0003-2461-232X Universidade do Estado de Minas Gerais, Brasil E-mail: milk.elly@hotmail.com

Valdilene Gonçalves Machado Silva ORCID: https://orcid.org/0000-0002-7262-6438 Universidade do Estado de Minas Gerais, Brasil E-mail: valdilenemachado@gmail.com

\begin{abstract}
Resumo
A aposentadoria é um assunto que tem deixado muitos brasileiros inseguros devido as mudanças nas regras do regime da previdência social ocorridas recentemente. Isso levará muitos indivíduos a buscarem alternativas para assegurar uma renda suficiente para sobreviver pós aposentadoria. Assim, a proposta deste estudo foi analisar o comportamento dos acadêmicos de uma universidade pública localizada em Minas Gerais, em relação à formação de reserva financeira para a aposentadoria. Os objetivos específicos foram descrever o perfil dos acadêmicos, verificar seu nível de conhecimento sobre educação financeira, analisar o seu comportamento financeiro e conhecer como pretendem formar uma reserva específica para aposentadoria. A hipótese foi que os acadêmicos ainda não consideravam importante a formação de uma reserva financeira para utilização na vida pós-laboral e por isso não faziam reserva para esse fim. Realizou-se uma pesquisa descritiva com abordagem quantitativa, cujas informações foram coletadas por questionário. Identificou-se que os pesquisados eram predominantemente jovens, do gênero feminino e já estavam inseridos no mercado de trabalho. Não utilizavam frequentemente o cartão de crédito, tinham controle sobre seus gastos, julgavam-se controlados na gestão de suas finanças e com conhecimento suficiente para uma gestão financeira adequada. Não possuíam muito conhecimento sobre previdência social e privada, conheciam, porém, investimentos como poupança, ações, bens móveis e imóveis. Apesar de considerarem importante a formação de uma reserva financeira para utilização na fase pós-laboral, ainda não tinham iniciado a formação dessa reserva, não obstante estudar numa universidade pública, por isso sem custo de mensalidade, e já estarem no mercado de trabalho.
\end{abstract}

Palavras-chave: Educação Financeira; Aposentadoria; Previdência.

\begin{abstract}
Retirement is an issue that has left many Brazilians unsure due to the changes in the rules of the social security regime that have occurred recently. This will lead many individuals to look for alternatives to ensure sufficient income to survive post-retirement. Thus, the purpose of this study was to analyze the behavior of academics at a public university located in Minas Gerais, in relation to the formation of a financial reserve for retirement. The specific objectives were to describe the profile of academics, verify their level of knowledge about financial education, analyze their financial behavior and learn how they intend to form a specific retirement reserve. The hypothesis was that academics still did not consider the formation of a financial reserve for use in post-work life important and therefore did not make a reserve for this purpose. A descriptive research with a quantitative approach was carried out, whose information was collected by questionnaire. It was identified that those surveyed were predominantly young, female and were already inserted in the job market. They did not use credit cards frequently, they had control over their spending, they considered themselves controlled in the management of their finances and with sufficient knowledge for adequate financial management. They did not have much knowledge about social and private pensions, however, they knew about investments such as savings, stocks, movable and real estate. Although they consider the formation of a financial reserve to be used in the post-employment phase important, they had not yet started the
\end{abstract}


formation of this reserve, despite studying at a public university, therefore without monthly fees, and already being in the labor market.

Keywords: Financial education; Retirement; Social security.

\section{Resumen}

La jubilación es un tema que ha dejado a muchos brasileños inseguros debido a los cambios en las reglas del régimen de seguridad social que se han producido recientemente. Esto llevará a muchas personas a buscar alternativas para garantizar ingresos suficientes para sobrevivir después de la jubilación. Así, el propósito de este estudio fue analizar el comportamiento de los académicos de una universidad pública ubicada en Minas Gerais, en relación a la formación de una reserva financiera para la jubilación. Los objetivos específicos fueron describir el perfil de los académicos, verificar su nivel de conocimiento sobre educación financiera, analizar su comportamiento financiero y conocer cómo pretenden formar una reserva de retiro específica. La hipótesis era que los académicos aún no consideraban importante la formación de una reserva financiera para su uso en la vida posterior al trabajo y, por lo tanto, no hicieron una reserva para este propósito. Se realizó una investigación descriptiva con enfoque cuantitativo, cuya información fue recolectada mediante cuestionario. Se identificó que los encuestados eran predominantemente jóvenes, mujeres y ya estaban insertos en el mercado laboral. No usaban tarjetas de crédito con frecuencia, tenían control sobre sus gastos, se consideraban controlados en el manejo de sus finanzas y con conocimientos suficientes para una adecuada gestión financiera. No tenían mucho conocimiento sobre pensiones sociales y privadas, sin embargo, conocían inversiones como ahorro, acciones, muebles e inmuebles. Si bien consideran importante la formación de una reserva financiera para ser utilizada en la fase post-empleo, aún no habían iniciado la formación de esta reserva, a pesar de estudiar en una universidad pública, por lo tanto sin cuotas mensuales, y ya estar en el mercado laboral.

Palabras clave: Educación financeira; Jubilación; Bienestar.

\section{Introdução}

As mudanças no atual regime da previdência social têm gerado insegurança e incertezas quanto ao futuro financeiro dos brasileiros, pois muitos que receberão os benefícios sociais ofertados pela previdência social não sabem ao certo por quanto tempo terão de contribuir ou se chegarão a aposentar-se no futuro.

A educação financeira voltada para a aposentadoria é um assunto pouco abordado no Brasil. Segundo Dietrich e Braido (2016), as pessoas hoje vivem mais e buscam conforto e melhor qualidade de vida. Esse fato gera a necessidade de precaver-se financeiramente para garantir uma estabilidade futura, uma vez que não se sabe ao certo como estará a economia daqui a alguns anos ou por quanto tempo a mais terão de contribuir para o Instituto Nacional de Seguridade Social (INSS) para receber os benefícios a que têm direito e se esses benefícios serão suficientes para suprir as suas necessidades econômicas.

Por meio da educação financeira é possível adquirir os conhecimentos necessários para tomada de decisões mais racionais em relação à vida financeira, de forma que os indivíduos alcancem a estabilidade financeira e, consequentemente, uma melhoria na qualidade de vida (Lizote, Simas Verdinelli \& Lana, 2010).

De acordo com a Organização para a Cooperação e Desenvolvimento Econômico e Comissão de Valores Mobiliários (OCDE \& CVM, 2005), os programas de educação financeira devem abordar questões de suma relevância que, a depender das circunstâncias nacionais, podem envolver temas importantes, como planejamento financeiro, poupança, gestão de dívidas, conscientização financeira, noções básicas de economia e matemática financeira. Para o autor também é necessário conscientizar os trabalhadores sobre a necessidade de avaliarem a adequação financeira de seus regimes de previdência pública e privada e a tomarem medidas apropriadas, quando necessário, para que, no fim da vida ativa, seja possível gozar de forma plena a sua aposentadoria.

Para Ferreira (2010, p. 178) aposentadoria é um “[...] estado de inatividade de funcionário público, ou funcionário de empresa particular, ao fim de certo tempo de serviço, com determinado vencimento", ou seja, um valor que será recebido pelo beneficiário após determinado período de contribuição.

Dados do Instituto Brasileiro de Geografia e Estatística (IBGE, 2010) indicam que o crescimento da expectativa de vida dos brasileiros e a redução na taxa de natalidade resultarão numa população mais idosa e, consequentemente, menos produtiva, isso somado ao déficit dos atuais números apresentados pela previdência social, daqui a alguns anos contar apenas 
com o benefício pago pela previdência social não será suficiente para se ter uma vida financeiramente confortável (Dietrich \& Braido, 2016).

Nessa perspectiva, este trabalho propõe-se a responder o seguinte questionamento: qual o comportamento financeiro os acadêmicos de uma instituição pública, localizada no centro oeste de Minas Gerais, adotam ou pretendem adotar, visando à formação de uma reserva financeira para a aposentadoria?

Para Cerbasi (2014) as pessoas não estão habituadas a fazer planos para o futuro porque não foram educadas para isso. O autor afirma ainda que os jovens são imediatistas e não se preocupam com o futuro, porque o amanhã parece ainda muito distante. Nesse sentido, adota-se como hipótese 1, que os acadêmicos que responderam a pesquisa, não têm consciência da importância da formação de uma reserva financeira para aposentadoria, e hipótese 2 os acadêmicos não fazem uma reserva para esse fim, porque, assim como a maioria dos brasileiros, não tiveram acesso a uma educação financeira adequada e por isso não pensam financeiramente no futuro.

Pensar na aposentadoria sem depender somente da previdência social é fundamental para garantir melhor qualidade de vida ao fim da vida laboral. Vale salientar que, durante as fases da vida, os gastos mudam. Ao envelhecer, por exemplo, há um aumento de despesas com planos de saúde e medicamentos, e essas questões precisam ser analisadas na juventude, pois é quando normalmente ocorre a formação do patrimônio e esse fato deve ser considerado.

A partir do problema levantado, definiu-se como objetivo geral analisar o comportamento dos acadêmicos de uma universidade pública, localizada no centro oeste de Minas Gerais, em relação à formação de reserva financeira para a aposentadoria. Adotaram-se, como objetivos específicos, descrever o perfil dos acadêmicos, verificar o seu nível de conhecimento em relação à educação financeira, analisar o seu comportamento financeiro e conhecer como pretendem, de fato, formar uma reserva específica para aposentadoria.

Esse trabalho justifica-se, pois, a partir de seus resultados, a comunidade acadêmica poderá ter mais consciência da importância da formação de uma reserva financeira para ser utilizada pós-aposentadoria, já que, segundo a Confederação Nacional de Dirigentes Lojistas (CNDL, 2019), apenas $41 \%$ da população alcançam a estabilidade nessa fase da vida. Contribuirá também para que a universidade possa, a partir de seus resultados, oferecer cursos de extensão, com o objetivo de capacitar as pessoas a elaborarem um planejamento financeiro eficaz, a terem um consumo mais consciente, o que poderá proporcionar-lhes maior estabilidade financeira no futuro. Outra contribuição deste trabalho é que poderá servir de reflexão para outras pessoas fora do âmbito acadêmico, que não se preocupam em como sobreviverão ao final de sua vida ativa.

Para melhor compreensão, este texto está assim organizado: a seção 1 trata desta introdução, que descreve o problema, hipótese, objetivos e a justificativa da pesquisa; a seção 2 aborda a educação financeira; a 3 trata da aposentadoria; a 4 discorre sobre investimentos financeiros; a 5 trata da metodologia utilizada; a seção 6 apresenta os resultados e sua discussão; na seção 7 fazem-se as considerações finais; e, por fim, são apresentadas as referências.

\section{Educação Financeira}

Segundo a OCDE e CVM (2005), educação financeira é um processo pelo qual o indivíduo faz escolhas conscientes, e busca conhecimentos a respeito de economia para melhor dispor de seu dinheiro. De acordo com Arcuri (2018), a educação financeira não está relacionada somente a calcular as despesas e receitas, ela também está interligada ao comportamento e à forma como se compreende o dinheiro e todas as informações relacionadas a ele. Saber ganhar, investir, economizar é a melhor maneira de garantir a liberdade e segurança financeira. Através da educação o indivíduo desenvolve novos hábitos de consumo e investimentos, ou seja, aprende a controlar os ganhos e os gastos.

"A educação financeira deve começar na escola. As pessoas devem ser educadas sobre questões financeiras o mais cedo possível em suas vidas" (OCDE \& CVM, 2005, p. 5). Mineghetti, Falceta, Rassier e Marchionatti (2017) também 
corroboram com esse pensamento, afirmando que a educação financeira é um eixo frágil da política financeira, sendo necessário que as pessoas tenham uma cultura financeira adequada e que todos tenham acesso aos serviços financeiros. Segundo os autores, é recomendado que a educação financeira seja ministrada nas escolas para que os jovens saiam do sistema escolar com um conhecimento amplo e profundo sobre as questões financeiras para que eles possam gerir de forma mais racional as finanças ao longo da vida, para que saibam fazer uma gestão eficiente das dívidas pessoais e uma avaliação adequada para a aposentadoria.

Na opinião de Wisniewski (2010), o indivíduo que têm consciência da importância de um bom planejamento financeiro poderá tomar decisões mais seguras. Conhecer os conceitos básicos de finanças, produtos financeiros e investimentos minimizam o impacto negativo que atitudes impensadas provocam nas finanças, no bem-estar pessoal, no desenvolvimento das economias e na sua sustentabilidade no longo prazo.

\section{Aposentadoria}

Em termos gerais, aposentadoria nada mais é do que a cessação do período de trabalho, e é um assunto de grande preocupação para milhares de brasileiros. Há algumas décadas as pessoas planejavam trabalhar por 30 ou 35 anos e então se aposentar e viver tranquilamente da renda adquirida ao longo dos anos de trabalho, atualmente, porém, isso parece ser algo distante a ponto de não se ter uma noção exata do que se esperar na vida pós-laboral (Cerbasi, 2014).

De acordo com França e Soares (2009), a expectativa de vida dos brasileiros é de 73 anos, sendo que cerca de quinze milhões de pessoas possuem sessenta anos ou mais. $\mathrm{O}$ autor ainda afirma que, ao longo das quatro décadas seguintes, a expectativa de vida atingirá 81 anos, isso significa que a população está vivendo mais, com melhor qualidade e custo de vida elevado, no entanto ninguém estará disposto a simplesmente aceitar um estilo de vida com escolhas limitadas pela falta de dinheiro.

Visando à proteção e à garantia da segurança da população brasileira diante dos riscos sociais, o art.194 da Constituição federal de 1988 assegura direitos à saúde, à previdência e à assistência social, que compõem o tripé da seguridade social (Constituição da República Federativa do Brasil, 1988).

Para Dietrich e Braido (2016), a previdência social tem por objetivo reconhecer e conceder direitos aos seus assegurados quando estes perdem a capacidade de trabalho, seja por velhice ou por outras limitações. As projeções futuras são preocupantes em virtude da finidade dos recursos para garantir o bem-estar da população que está envelhecendo, sendo assim, uma série de medidas devem ser tomadas para que no futuro se possa, pelo menos, viver com segurança e estabilidade. Tanto para Segundo Filho (2003), quanto para Hoji (2011), o planejamento financeiro deve começar o mais rápido possível, pois os indivíduos que o fazem conseguem melhores resultados e mais tempo para aproveitar a aposentadoria.

Sendo assim, o planejamento estratégico pessoal contribui para o planejamento de uma aposentadoria com mais segurança e estabilidade.

\subsection{Planejamento estratégico para a aposentadoria}

Segundo Macedo Júnior (2013, p. 26), o planejamento financeiro é o “[...] processo de gerenciar seu dinheiro com o objetivo de atingir a satisfação pessoal". Na visão de Hoji (2011), o planejamento estratégico é uma ferramenta muito utilizada para planejamento de longo prazo, e está dividido em três elementos básicos: a antevisão, estratégia e implementação. Conforme o autor, antevisão é o que se espera alcançar, o seu objetivo. Estratégia é o caminho que leva alcançar o futuro imaginado e, por último, a implementação, que nada mais é do que a conduta que reflita a estratégia definida.

O ideal é que, ao aposentar-se, a pessoa tenha um patrimônio acumulado que lhe permita ter o padrão de vida desejado ou pelo menos manter o padrão atual. Para Hoji (2011) o valor aproximado de renda para aposentadoria para manter- 
se o mesmo padrão é em torno de $3 / 4$ ou (75\%) da renda que se tinha antes da aposentadoria. O autor exemplifica que, se a renda mensal for de cinco mil reais, o indivíduo precisará de pelo menos 3,8 mil e afirma que, levando em consideração que parte da renda será paga pelo sistema de previdência social, se a pessoa mantiver a contribuição necessária para aposentadoria, o patrimônio restante deverá gerar uma renda complementar.

Com o intuito de manter o bom estilo de vida e alcançar uma renda complementar à da previdência social, de acordo com Arcuri (2018), Hoji (2011), Cerbasi (2014) e Wisniewski (2010), o melhor planejamento financeiro é poupar dinheiro.

Para Garcia (2005) o consumo, a renda e a poupança estão interligados, pois a renda que a pessoa receberá no fim da vida laboral será diretamente proporcional ao quanto ela poupou na fase ativa da vida. Para o autor a poupança é a parte da renda pessoal que não é gasta em consumo. Já para Segundo Filho (2003) poupança é o primeiro passo para garantir a aposentadoria.

De acordo com Braido (2014), alunos do curso de gestão de uma Instituição de Ensino Superior (IES), do Rio Grande do Sul, realizavam seu planejamento pessoal, preocupavam-se com o planejamento pessoal e pretendiam aderir a um plano de previdência privada nos anos seguintes.

Para Mallmann (2004), de acordo com pesquisa realizada, a maioria das pessoas preocupava-se com a situação financeira da previdência social e por isso buscavam novas formas de geração de renda.

\subsection{A previdência social}

Num primeiro momento é preciso considerar que os direitos relativos à previdência social se encontram inseridos nos denominados direitos fundamentais sociais, em conformidade com o disposto pelo art. 6 da Constituição federal de 1988, referem-se aos direitos à educação, saúde, trabalho, lazer, moradia, segurança, proteção à maternidade e à infância, assistência aos desamparados e previdência social. Trata-se basicamente de uma espécie de prestação positiva que é proporcionada pelo Estado, atuando de modo indireto ou direito, por meio de normas constitucionais que se destinam principalmente a possibilitar melhores condições de vida para aqueles que são desprovidos de recursos. Dessa maneira, trata-se de uma forma de realizar a igualização de situações que são desiguais, em síntese, podem ser considerados direitos que se vinculam ao direito de igualdade (Nolasco, 2012).

Torres (2012) destaca que a Previdência Social pode ser considerada como uma espécie de técnica de proteção social que se destina principalmente ao afastamento das necessidades sociais, que são decorrentes das contingências sociais, estas, por sua vez, acabam por reduzir ou até mesmo eliminar a capacidade dos trabalhadores de autossustentarem, bem como aos seus dependentes. Diante de tal cenário, tem-se, pois, que a Previdência Social se destina a contingências específicas, tais como aquelas que acabam por atingir o trabalhador e, consequentemente, promover reflexos na sua vida e também na de seus dependentes, que são pessoas consideradas economicamente dependentes do segurado:

Previdência Social não se confunde com Seguridade Social no direito brasileiro. Isso a Constituição Federal de 1988 deixou muito claro no art. 194, que estabelece ser a Seguridade Social um conjunto integrado de ações de iniciativa dos Poderes Públicos e da sociedade destinadas a assegurar os direitos relativos à saúde, à Previdência e à assistência social. Portanto, a Previdência Social é um dos componentes da Seguridade Social no Brasil, visando ao auxílio financeiro, dando cobertura às mais diversas situações da vida do segurado, como a doença, a velhice, a invalidez, a prisão, a maternidade, o desemprego involuntário, através de benefícios àqueles que tenham contribuído na forma dos planos previdenciários. Entretanto, o termo Seguridade Social aparece em outros países como sinônimo de Previdência Social. (Nolasco, 2012, p. 1.)

Vale ressaltar, por fim, que o art. 201 da Constituição federal de 1988 dispõe que a previdência deverá ser organizada, sob a forma de regime geral, num caráter contributivo e com filiação obrigatória, observando os critérios que preservem o equilíbrio financeiro e atuarial. Em resumo, tem-se que a Previdência Social pode ser definida como uma espécie de poupança 
obrigatória, para garantir que este tenha condições financeiras para usufruir a vida em sociedade, ao fim de sua vida ativa, seja pela idade ou por eventos que aconteçam ao longo da vida do ser humano (Constituição da República Federativa do Brasil, 1988).

Nesse cenário destaca-se ainda a previdência privada que atualmente tem sido uma excelente alternativa para as pessoas que buscam complemento para a vida pós-laboral.

\subsection{Previdência privada}

Uma das opções para formação de uma reserva para utilização após a aposentadoria é a contratação de um plano de previdência complementar.

O Regime de Previdência Complementar - RPC tem por finalidade proporcionar ao trabalhador uma proteção previdenciária adicional àquela oferecida pelo Regime Geral de Previdência Social - RGPS ou pelo Regime Próprio de Previdência Social - RPPS, para os quais as contribuições dos trabalhadores são obrigatórias. (Secretaria Especial de Previdência e Trabalho, 2020, p. 1)

No RPC o benefício será pago de acordo com as reservas (poupança) acumuladas pelo trabalhador ao longo dos anos, pelo regime de capitalização. Esse sistema é composto por dois segmentos: o aberto, operacionalizado pelas Entidades Abertas de Previdência Complementar e fiscalizado pela Superintendência de Seguros Privados (Susep), e o fechado, operacionalizado pelas Entidades Fechadas de Previdência Complementar e fiscalizados pela Superintendência Nacional de Previdência Complementar (Previc) (Secretaria Especial de Previdência e Trabalho, 2020)

De acordo com a Susep, os planos de previdência complementar têm o propósito de assegurar o "[...] pagamento de um benefício ao próprio participante do plano (coberturas por sobrevivência ou de invalidez) ou aos seus beneficiários (coberturas de morte)." (Superintendência de Seguros privados [SUSEP], 2020, p. 1)

Portanto, previdência privada não é um investimento, ela é uma aposentadoria que não está ligada à previdência social; diferem-se, considerando que a previdência social é de caráter público e obrigatório, e a previdência privada é de caráter voluntário e opcional, criada para suplementar os benefícios da seguridade social. Nos planos de previdência privada existe a possibilidade de se escolherem o valor e o período em que ela será feita, e o valor que será recebido no futuro será proporcional ao valor e ao tempo de contribuição (Fulgêncio, 2007).

A previdência privada aberta pode ser de dois tipos. Um deles é o Plano Gerador de Benefícios Livres (PGBL). Essa modalidade é indicada para pessoas que fazem declaração de imposto de renda completa, pois o valor depositado em todos os meses pode ser deduzido da base de cálculo do imposto de renda e, nessa situação, o indivíduo pode ter um aumento no valor da restituição do imposto de renda. O outro tipo é o Vida Gerador de Benefícios Livre (VGBL), que é indicado para quem faz a declaração do imposto de renda simplificada, cuja vantagem é que o desconto do imposto de renda é feito somente sobre os rendimentos (Santos, 2019).

As Entidades Fechadas de Previdência Complementar (Fundos de Pensão) são “[...] responsáveis por administrar e operar planos de benefícios previdenciários criados por empresas (patrocinadores) para seus empregados (participantes) ou por pessoas jurídicas de caráter profissional, classista ou setorial (instituidores) para seus associados." (Secretaria Especial de Previdência e Trabalho, 2020, p. 1)

De acordo com o texto constitucional, a previdência privada deve ser organizada de maneira autônoma ao regime geral de previdência, sendo essa modalidade facultativa, bem como regulamentada por legislação complementar. Destaca-se ainda que, na previdência complementar fechada, as contribuições realizadas pelo empregador, tal como os benefícios e as condiçõesnão fazem parte do contrato de trabalho dos parcipantes. Além disso, toda e qualquer contribuição paga pelo sujeito 
ao plano previdenciário não podem fazer parte de sua remuneração, portanto não representam um salário indireto (Marques, Monteiro \& Freitas, 2014).

Santos (2019) salienta que, ao pensar em adquirir um plano de previdência privada, é importante analisar as opções oferecidas pelo mercado, pois os planos costumam possuir além das taxas de administração, uma taxa de saída no momento do resgate e taxa de carregamento. Deve ser avaliada também a rentabilidade do plano, pois existem no mercado ofertas de investimentos que possuem melhores rentabilidades e taxas menores.

Outra opção de geração de renda são os investimentos financeiros. O mercado financeiro oferece várias opções de se montar uma carteira de investimentos, que podem ser em renda fixa ou variável.

\section{Investimentos para Formação de Reserva Financeira}

$\mathrm{Na}$ atualidade muito se fala sobre investimentos; a necessidade de acumularem-se recursos torna-se cada vez mais importante, pois com crises econômicas e transições de governos não se sabe como o Brasil ficará economicamente.

Segundo Cerbasi (2013), investir nada mais é do que fazer aplicações de recursos financeiros com o objetivo de se ter maior rentabilidade, visando sempre ao aumento do patrimônio. É importante num investimento sempre avaliar o seu grau de risco, pois, quanto maior a rentabilidade, maior tende a ser o risco. O risco de crédito está diretamente ligado à capacidade que a instituição financeira tomadora do recurso tem de devolvê-lo dentro do prazo e das taxas estabelecidas no ato da contratação. Os investimentos normalmente têm seus prazos preestabelecidos no momento da compra, e, caso o prazo não seja cumprido, necessitando o indivíduo retirar o dinheiro antes, isso poderá acarretar perda de recursos.

Domingos (2013) orienta que, formar uma reserva de emergência é uma das primeiras atitudes de um investidor, sendo que essa reserva financeira deverá ser suficiente para gerar o dobro de rendimentos necessários para manter o padrão de vida atual. Para formação dessa reserva o mercado financeiro oferece diversos produtos.

\subsection{Produtos financeiros}

Segundo Hoji (2011), os investimentos financeiros podem ser divididos em aplicações financeiras de renda fixa e de renda variável.

O tesouro direto, em linhas gerais, refere-se a um programa de venda de títulos públicos para pessoas físicas. Foi criado no ano de 2002 pelo Tesouro Nacional em parceria com a BM\&FBovespa, tendo por finalidade a captação de recursos, a fim de financiar a dívida pública, bem como os investimentos do governo. Existem basicamente três maneiras de se realizarem as operações no Tesouro Direto. Uma delas é por meio do site do Tesouro Direto; outra é por meio de um agente de custódia autorizado pelo investidor, ou ainda pelo site do agente de custódia, uma vez que corretoras e também instituições financeiras possuem vinculação com o Tesouro, e dessa maneira tornam-se possíveis as operações (Aranha \& Sacramento, 2013). As vantagens do programa é a segurança, pois é um investimento garantido pelo Tesouro Nacional, a flexibilidade que se tem por ter a possibilidade de personalizar uma carteira de investimentos de acordo com o objetivo, o baixo custo, pois possui apenas a taxa da instituição financeira e a taxa de custódia cobrada pela BM\&FBovespa e a comodidade, pois todas as operações podem ser feitas pela internet (Portal do Investidor, 2020).

De acordo com o Tesouro Direto (2019), a criação do programa teve como objetivo tornar acessível uma das melhores opções de investimentos em renda fixa, o que, antes de sua criação, era possível apenas por meio de instituições financeiras. Os títulos públicos são ofertados quando o governo necessita de recursos financeiros para financiar a dívida pública e são resgatados pelos investidores acrescidos de juros em data futura.

Outra opção de aplicação em renda fixa é o Certificado de Depósito Bancário (CDB), que é uma modalidade em que o investidor empresta para o agente financeiro o seu excedente financeiro. 
O tipo de renda variável mais comum, de acordo com BMF\&Bovespa (2016), são as ações, que são emitidas pelas sociedades anônimas de capital aberto e que dão aos investidores uma participação no capital social da empresa. Elas podem ser ordinárias $(\mathrm{ON})$ ou preferenciais $(\mathrm{PN})$. As ordinárias dão ao investidor o direito de participar e votar nas assembleias de acionistas, já as preferenciais dão preferência ao investidor no recebimento de dividendos. O Fundo de Investimento Imobiliário (FII), segundo a BMF\&Bovespa (2016), são recursos destinados à aplicação em ativos no mercado imobiliário. O administrador, que poderá ser uma instituição financeira específica, iniciará o fundo e é de sua responsabilidade o processo de captação de recursos entre os investidores com a venda de cotas. Os recursos captados na venda das cotas deverão ser utilizados para compras de imóveis rurais ou urbanos destinados a fins comerciais ou residenciais. Têm como vantagens a diversificação em ativos do mercado imobiliário em vários tipos de imóveis e também permitem que o investidor tenha ativos relacionados ao mercado imobiliário sem precisar de fato comprar um imóvel.

\section{Metodologia de Pesquisa}

O estudo em questão foi realizado em uma unidade de uma universidade pública localizada no centro oeste Mineiro. Atualmente a unidade oferece os cursos de administração com 156 alunos, o curso de ciências contábeis com 159, o curso de pedagogia com 118 e o curso de serviço social com 61, perfazendo um total de 494 alunos.

Esta pesquisa caracteriza-se quanto aos objetivos como a descritiva, pois o propósito foi demonstrar o comportamento financeiro dos acadêmicos da unidade pesquisada em relação à formação de uma reserva financeira para a aposentadoria. Segundo Bertucci (2008), pesquisas descritivas são aquelas com o intuito de relatar ou descrever uma situação. Quanto à abordagem, classifica-se como quantitativa, pois, por meio da aplicação de um questionário, foi possível entender o que pensam os acadêmicos em relação à sua sobrevivência em fase pós-laboral. Segundo Pereira (2012), a pesquisa quantitativa propõe-se a transformar as informações em números, para que seja possível classificá-las e analisá-las.

Quanto aos procedimentos técnicos, classificou-se como estudo de caso. O estudo de caso, de acordo com Gil (2016), tem por característica o estudo exaustivo e profundo de um objeto, ou seja, um olhar mais aprofundado de um ambiente ou de uma situação em particular.

Os dados foram levantados por meio de um questionário, que é definido pelo número de questões que são apresentadas as pessoas, tendo por objetivo conhecer crenças, valores, opiniões, expectativas e outras informações (Gil, 2007). Neste estudo, o questionário foi formado por questões objetivas e foi aplicado pelas próprias pesquisadoras, com autorização do professor do dia, aos acadêmicos que estavam presentes em sala de aula.

O questionário continha perguntas fechadas para identificar o perfil dos acadêmicos de cada um dos cursos, conhecer o nível de conhecimento que possuíam sobre educação financeira, investimentos e aposentadoria; saber quais os tipos de investimentos mais utilizados por eles, além de avaliar se possuíam conhecimento e conscientização sobre a importância de geração de renda para formação de uma reserva financeira para ser utilizada no futuro na fase pós-laboral.

As três variáveis focadas neste projeto são:

1) Nível de conhecimento sobre educação financeira: conhecimentos básicos sobre educação financeira, métodos de investimento, orçamento familiar para aposentadoria. Estes conceitos foram mensurados por meio de questões objetivas.

2) Atitudes dos indivíduos em relação às decisões financeiras: essas questões referem-se às reações dos indivíduos em sua vida financeira. O objetivo é avaliar quais fatores influenciam as decisões de consumo e poupança, ou seja, se, apesar dos conhecimentos em finanças, as pessoas ainda tomam decisões baseadas apenas em suas experiências.

3) Preocupação dos alunos com a aposentadoria e em como sobreviverão ao final de sua vida ativa. 


\subsection{Universo de pesquisa e delineamento amostral}

A população de pesquisa é o conjunto definido de elementos que possuem determinadas características. De forma mais rigorosa, "[...] trata-se do conjunto de indivíduos ou objetos que apresentam em comum determinadas características definidas para o estudo" (Martins, 2006, p. 185). A amostra é o subconjunto por meio do qual se estabelecem ou se estimam as características do universo.

Segundo Martins (2006), há duas formas de amostragem: probabilística e não probabilística. A amostragem probabilística é aquela em que todos os elementos da população têm uma probabilidade conhecida e diferente de zero de pertencer à amostra. Sendo assim, a pesquisa apresenta como procedimento amostral um tipo específico de amostragem probabilística: a amostragem estratificada.

A amostragem estratificada diz respeito ao processo em que se divide a amostra em estratos que são subpopulações mais ou menos homogêneas (Martins, 2006).

Assim, o cálculo do tamanho da amostra (n) foi realizado por meio dos delineamentos de Martins (2006) e Gil (2007) utilizando a amostragem estratificada (tamanho da amostra aleatória estratificada para estimar uma proporção de população finita).

Para tanto, considerou-se um Erro máximo permitido de 5\%, um Nível de Confiança de 95\% e uma proporção $p$ estimada de $50 \%$.

Delineamento amostral

$$
n=\frac{\sum_{i=1}^{k}\left(\frac{N_{i}^{2} p_{i} q_{i}}{w_{i}}\right)}{N^{2}\left(\frac{e^{2}}{Z_{\alpha / 2}^{2}}\right)+\sum_{i=1}^{k} N_{i} p_{i} q_{i}}
$$

Em que:

$n=$ tamanho total da amostra;

$N=$ total de alunos;

$N_{\mathrm{i}}=$ total de alunos no curso i;

$w_{i}=\mathrm{N}_{\mathrm{i}} / \mathrm{n}$;

$p=$ proporção estimada em que o fenômeno se apresenta e $q=1-p$;

$Z_{\alpha / 2}=$ é o valor tabelado para um nível de confiança de $95 \%$ - normal padrão;

$e=$ erro máximo permitido - erro amostral.

AMOSTRA $=271$

Para a determinação da amostra em cada estrato utilizou-se da repartição proporcional (Neder, 2008). A quantidade de estudantes amostrados por curso está demonstrada na Tabela 1.

Tabela 1 - Quantidade de alunos amostrados por curso.

\begin{tabular}{|l|c|l|l|}
\hline \multicolumn{1}{|c|}{ Estrato } & Quant. Discentes & Porcentagem & Amostragem \\
\hline Administração & 156 & $31,58 \%$ & 86 \\
\hline Ciências Contábeis & 159 & $32,19 \%$ & 87 \\
\hline Pedagogia & 118 & $23,89 \%$ & 65 \\
\hline Serviço Social & 61 & $12,35 \%$ & 33 \\
\hline Total & 494 & $100,00 \%$ & 271 \\
\hline
\end{tabular}

Fonte: Autoras (2019). 
Observa-se que o quantitativo de estudantes amostrados do curso de Administração e Ciências Contábeis é praticamente o mesmo.

\section{Análise e Discussão dos Dados}

Neste trabalho utilizou-se de estatística descritiva para a organização, sumarização e descrição dos conjuntos de dados (Martins, 2006) por meio da construção gráficos de distribuição de frequência.

A unidade acadêmica pesquisada possuia 494 alunos matriculados; deste total, 292 participaram da pesquisa, perfazendo um total de 59,10\%, uma amostra relevante, uma vez que mais da metade dos acadêmicos respondeu ao questionário, sendo 86 alunos de administração (29,45 \%), 95 de ciências contábeis (32,54\%), 37 de serviço social (12,67\%) e 74 de pedagogia $(25,34 \%)$.

Inicialmente o interesse desta pesquisa foi conhecer o perfil dos acadêmicos. Identificou-se que 75,5\% deles eram do gênero feminino e 24,5\% do masculino; 31,7\% tinham até vinte anos de idade, $43,8 \%$ tinham entre 21 e 25 anos, $13,8 \%$ entre 26 a trinta anos e 10,7\% tinham acima de trinta anos. A grande maioria dos alunos (90,7\%) já estava inserida no mercado de trabalho, exercendo alguma atividade remunerada. Percebeu-se, dessa forma, que os acadêmicos pesquisados, eram predominantemente jovens do gênero feminino que possuíam até 25 anos de idade e já estavam inseridos no mercado de trabalho.

O segundo grupo de perguntas foi para verificar o nível de conhecimento que os acadêmicos tinham sobre educação financeira. Questionados sobre como se sentiam em relação ao seu nível de conhecimento para gerenciar o seu próprio dinheiro, identificou-se que grande parte dos alunos $(48,6 \%)$ se considerava razoavelmente segura, $29,3 \%$ não se sentiam muito seguros, $11,7 \%$ não se sentiam nada seguros e 10,3\% se consideravam muito seguros. O resultado é coerente, considerando que a pesquisa foi realizada numa universidade que possuía os cursos de administração e ciências contábeis, os quais possuem em seus currículos disciplinas relacionadas à gestão financeira. Numa pesquisa realizada em um IES do Rio Grande do Sul, Braido (2014) observou que, nos cursos da área de gestão e correlatas, os alunos apresentaram um nível mais elevado de conhecimento sobre finanças pessoais do que os demais cursos, fato também identificado nesta pesquisa.

No que tange aos conhecimentos sobre previdência privada e previdência social, a pesquisa apontou que 55,2\% dos pesquisados conheciam pouco sobre a previdência social, 38,3\% conheciam bem e 6,6\% não conheciam nada sobre previdência social. Em relação à Previdência privada, $61,7 \%$ conheciam pouco, $24,1 \%$ conheciam bem e $14,1 \%$ não conheciam nada.

A pergunta seguinte foi para saber o nível de conhecimento dos discentes em relação aos tipos de investimentos oferecidos pelo mercado financeiro e que poderiam ser utilizados para formação de uma reserva para utilização na aposentadoria. Nessa questão foi apresentada aos alunos uma lista dos investimentos mais conhecidos no mercado financeiro e foi solicitado a eles que marcassem todos aqueles que eles conheciam, sendo assim, poderiam marcar mais de uma opção. Foi disponibilizado também um espaço para que informassem algum outro tipo de investimento que não constava na lista apresentada. A grande maioria dos alunos (66,6\%) disse ter conhecimento da poupança, 53,1\% conheciam a previdência privada, 50,3\% conheciam investimentos em bens móveis e imóveis e 46,6\% conheciam também outros tipos investimentos financeiros que não haviam sido relacionados. Percebeu-se que grande parte dos alunos tinha conhecimento de investimentos que pareciam apropriados para formação de uma reserva financeira para a vida pós-laboral, como previdência privada e imóveis, apesar de já terem afirmado em resposta anterior que não tinham conhecimento de previdência privada.

Percebeu-se uma contradição na resposta dos alunos em relação ao nível de conhecimento sobre previdência privada. Quando perguntados o quanto conheciam sobre previdência privada, 75,8\% afirmaram que conheciam pouco ou não conheciam nada desse produto quando perguntados, porém, sobre os tipos de investimentos que mais conheciam e que 
poderiam ser utilizados para formação de uma reserva financeira para ser utilizada no futuro, o produto apontado como o segundo mais conhecido foi a previdência privada. Dessa forma, entende-se que, apesar de constar da lista dos mais conhecidos, na verdade os respondentes possuíam um conhecimento superficial sobre ele. Quanto à poupança, acredita-se que eles realmente tenham um bom nível de conhecimento, por tratar-se de um investimento simples e tradicional, conforme afirma Megliori e Vallin (2009).

O terceiro bloco de perguntas foi para conhecer o comportamento financeiro dos alunos e saber como eles pretendiam, de fato, formar uma reserva financeira para ser utilizada após a aposentadoria.

Para saber se os alunos tinham um consumo consciente, foram feitas três perguntas referentes ao consumo. Em relação à frequencia de utilização do cartão de crédito, 15,2\% responderam que sempre o utilizavam, 23,8\% utilizam-no muitas vezes, $34,5 \%$ algumas vezes e $26,6 \%$ nunca utilizaram cartão de crédito. Com referência ao parcelamento das compras pelo cartão de crédito, $10 \%$ sempre parcelavam as compras, $14,8 \%$ parcelavam muitas vezes, $42,1 \%$ parcelavam algumas vezes e $33,1 \%$ nunca parcelavam. Observou-se, portanto, que os acadêmicos eram controlados em relação à utilização do cartão de crédito.

O questionamento sequinte foi para saber se os discentes conseguiam arcar com suas despesas mensais apenas com sua renda. Obteve-se que $46,9 \%$ conseguiam pagar suas despesas pessoais e ainda poupavam uma parte, $41 \%$ conseguiam pagar todas as suas despesas, mas não conseguiam guardar dinheiro. Para 7,2\% a sua renda mensal não era suficiente para pagar as contas e por isso utilizavam o limite do cartão de crédito, 2,4\% gastavam toda a sua renda e ainda pediam dinheiro emprestado para familiares e amigos, e outros $2,4 \%$ não possuíam renda. Constatou-se, dessa forma, que a grande maioria conseguia fazer uma gestão financeira pessoal eficiente, pois possuía independência financeira e uma parte significativa deles $(46,9 \%)$ ainda fazia poupança com parte de sua renda.

Outro interesse da pesquisa foi saber como os respondentes definiam seu perfil de consumo. Identificou-se que 7,2\% se consideravam com perfil compulsivo para compras, pois compravam sem pensar nas consequências; 17,9\% definiram-se como descontrolados, pois compravam sem necessidade; $44,1 \%$ como controlados, pois não se arriscavam em assumir dívidas; e 30,7\% se consideravam equilibrados, pois só compravam de acordo com a sua necessidade. Verificou-se que os alunos que responderam a pesquisa praticavam o consumo consciente e racional. Gonzalez (2018) comenta que pesquisa realizada pelo Instituto Akatu apontou que 76\% dos entrevistados, que eram homens e mulheres com idade acima de dezesseis anos, não tinham o consumo consciente. "Entre os mais conscientes, $24 \%$ têm mais de 65 anos, $52 \%$ são da classe $\mathrm{AB}$ e $40 \%$ possuem ensino superior" (Gonzalez, 2018, p. 1). Acredita-se que os discentes pesquisados praticavam o consumo consciente por cursar o ensino superior, conforme apontado por Gonzalez (2018), e considerando que os cursos de administração e ciências contábeis, que possuíam o maior número de alunos, ofereciam disciplinas relacionadas à gestão financeira.

Outro questionamento foi sobre quais os investimentos eles faziam com o objetivo de formar uma reserva financeira para aposentadoria; 49,3\% responderam que faziam poupança, 17,2\% faziam previdência privada, $11,7 \%$ responderam que faziam outros tipos de investimentos financeiros e 30\% não guardavam dinheiro para esse fim. Segundo Gitman e Joehnk (2005), os investimentos que visam à acumulação de recursos para a aposentadoria são os mais importantes.

Observou-se mais uma contradição nas respostas. Os acadêmicos afirmaram que tinham conhecimento suficiente para gerir suas finanças, o produto financeiro, porém, no qual eles mais investiam era a poupança, um ativo com um rendimento baixo, que rende em média 3,0 \% ao ano. De acordo com Goeking (2018), a poupança é o pior investimento do ano e, apesar disso, a maioria dos brasileiros ainda continua deixando dinheiro guardado na poupança, em vez de buscar outras fontes de investimento que sejam tão conservadoras quanto a poupança, mas, com a maior rentabilidade. Assim, como a maioria dos brasileiros, os acadêmicos da unidade pesquisada não conhecem as opções de investimentos que o mercado financeiro oferece e que sejam tão seguras quanto a poupança, mas oferece uma rentabilidade maior. 
Sobre o quão importante os discentes consideravam a formação de uma reserva financeira para ser utilizada em sua vida pós-laboral, obteve-se que $87,6 \%$ consideravam importante e 10,3\% ainda não haviam pensado sobre esse assunto. Observou-se, portanto, que grande parte deles tinha consciência da importância de formação de uma reserva financeira para ser utilizada no futuro, considerando que ela traz benefícios como tranquilidade e segurança para a velhice. Esse fator é destacado por Dietrich e Braido (2016) quando afirmam que os indivíduos que possuem conhecimento sobre educação financeira, que fazem uma carteira de investimento para formação de uma reserva financeira para o futuro ou contratam um plano de previdência privada, conseguirão alcançar uma estabilidade financeira maior e mais rápida do que as pessoas que não fazem nenhum investimento.

Para identificar se os alunos se preocupavam em como sobreviverão após a aposentadoria, constatou-se que 44,5\% já pensavam em começar a poupar dinheiro para esse fim, 22,2\% responderam que para eles essa não era uma questão importante, $15,4 \%$ já tinham um plano de previdência privada, 14,6\% já faziam uma poupança para assegurar a aposentadoria e 3,3\% pretendiam ter apenas a aposentadoria do governo. Nesse aspecto notou-se que os acadêmicos, em sua maioria, afirmavam que tinham consciência da importância da formação de uma reserva para ser utilizada no futuro, grande parte deles já pensavam em fazer essa reserva financeira, mas ainda não tinham iniciado. Acredita-se que os acadêmicos, apesar de afirmarem que consideravam importante a formação de uma reserva financeira para ser utilizada no futuro, adotavam a mesma atitude dos jovens destacados por Cerbasi (2014), ou seja, que eram imediatistas e por isso não pensavam na aposentadoria por considerar um futuro ainda muito distante.

O Gráfico 1 demonstra quando os acadêmicos pretendiam iniciar a formação de uma reserva financeira para utilização ao final da vida laboral.

Gráfico 1 - Época em que os acadêmicos pretendem iniciar a formação da reserva financeira.

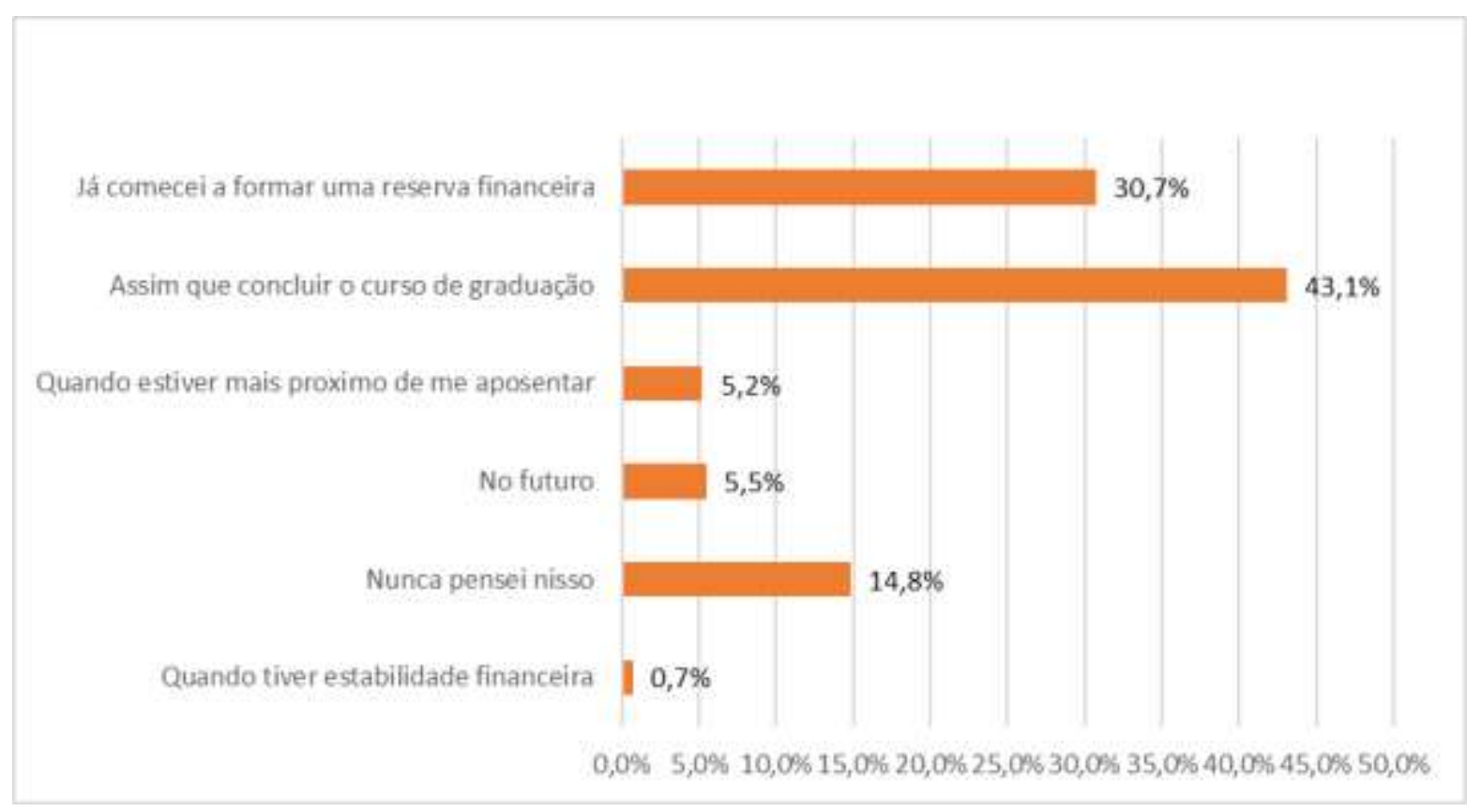

Fonte: Autoras (2019).

Chamou a atenção, conforme apresentado no Gráfico 1, que 30,7\% já iniciaram a formação da reserva e que 43,1\% pensavam em começar assim que terminassem a graduação. Constatou-se que os alunos reconheciam a importância da formação de uma reserva financeira para utilização no futuro, mas grande parte afirmou que começaria a formação dessa reserva somente quando terminasse a graduação, portanto entende-se que essa procrastinação seja por quê, de fato, eles viam a 
aposentadoria como algo ainda muito distante de sua realidade e o seu perfil imediatista levava-os a postergarem o início da formação dessa reserva. Outro aspecto que reforça essa conclusão é o fato da pesquisa ter sido realizada em uma universidade pública, em que os alunos não tinham custos com mensalidades, a maioria residia na mesma cidade na qual estudava, e a grande maioria deles já trabalhava. Segundo Filho (2005), Gitman e Joehnk (2005) destacam que o planejamento de uma reserva financeira para aposentadoria deve começar o mais cedo possível. Para Cherobim e Espejo (2010) o indivíduo pode ter seu futuro financeiro comprometido por não realizar um planejamento financeiro adequado, uma vez que este futuro depende da disciplina e responsbilidade presentes.

Outra contradição observada nas respostas dos alunos foi que, apesar de a grande maioria alegar que sabiam o que fosse educação financeira, já estivesse trabalhando, possuir controle sobre seus gastos e ter consciência da importância da formação de uma reserva para geração de renda após a aposentadoria, apenas a minoria (30,7\%), de fato, tinha a disciplina de poupar com a finalidade de formar uma reserva financeira para ser utilizada após a aposentadoria. Segundo Lizote, Simas, Verdinelli e Lana (2010), não adquirir os conhecimentos necessários para a correta gestão dos recursos financeiros, dificilmente concederá aos indivíduos uma estabilidade financeira segura.

\section{Considerações Finais}

Os dados levantados e analisados permitiram alcançar os objetivos propostos neste trabalho. Identificou-se que os acadêmicos da unidade pesquisada, eram predominantemente jovens do gênero feminino que possuíam até 25 anos de idade e já estavam inseridos no mercado de trabalho. A maior parte deles possuía conhecimentos sobre educação financeira e por isso se sentiam seguros para gerir suas finanças pessoais e praticavam o consumo consciente e racional.

Verificou-se que os alunos reconheciam a importância da formação de uma reserva financeira para utilização na fase pós-laboral. Alguns já tinham iniciado a formação dessa reserva, mas uma parte significativa deles pensava em começar a formação dessa reserva somente após a conclusão da graduação. Acredita-se, porém, que essa procrastinação seja porque eram jovens e, por isso, imediatistas, ou seja, não pensavam na aposentadoria, por considerar um futuro ainda muito distante.

Eles possuíam pouco conhecimento sobre previdência privada e previdência social e o tipo de investimento que eles mais conheciam e no qual mais aplicavam seus recursos para formação de uma reserva financeira era a poupança, que é um investimento de baixíssimo risco e por isso com baixa rentabilidade, considerado pelos analistas econômicos como o pior tipo de investimento atualmente. Assim, acredita-se que eles não tinham muito conhecimento sobre os diversos tipos de investimentos existentes para formação de uma reserva financeira, por isso continuavam com aplicações em poupança.

Os acadêmicos eram controlados na utilização do cartão de crédito, pois o utilizavam de forma moderada e não tinham o hábito de fazer compras parceladas no cartão. A maior parte deles tinha independência financeira, pois sua renda mensal era suficiente para arcar com suas despesas, e uma parte significativa ainda fazia poupança com uma parte da renda.

Concluiu-se, portanto, que a hipótese 1 , foi rejeitada, pois, conforme resultados da pesquisa, os estudantes tinham conhecimentos sobre educação financeira e consciência sobre a importância da formação de uma reserva financeira para utilização em sua vida pós-laboral, e a hipótese 2 foi aceita, pois os acadêmicos não pensavam, porém, financeiramente no futuro, pois a maioria ainda não tinha iniciado a formação dessa reserva, apesar de já estar no mercado de trabalho e possuir independência financeira.

Para pesquisas futuras, sugere-se realizar esta mesma investigação em outras unidades da universidade pública e em instituições privadas para comparação dos resultados. 


\section{Referências}

Aranha, A. B. J., \& Sacramento, F. J. S. (2013). Tesouro direto: Estudo com os professores da Faculdade de Administração e Ciências Contábeis de São Roque. Revista Econômica Gestão de negócios, 4(1), http://docs.uninove.br/arte/fac/publicacoes/pdf/v4-n1-2013/Ana_Bruna.pdf

Arcuri, N. (2018). Me poupe! Dez passos para nunca mais faltar dinheiro no seu bolso. Sextante

Bertucci, J. L O. (2011). Metodologia básica para elaboração de trabalhos de conclusão de cursos: ênfase na elaboração de TCC de pós-graduação lato sensu. São Paulo: Atlas.

BM\&F Bovespa (2016). Ações. http://www.bmfbovespa.com.br/pt_br/produtos/listados-a-vista-e-derivativos/renda-variavel/acoes.htm\#panel1a

BM\&F Bovespa (2016). Fundos De Investimento Imobiliário. Http://Www.Bmfbovespa.Com.Br/Pt_Br/Produtos/Listados-A-Vista-E-Derivativos/RendaVariavel/Fundos-De-Investimento-Imobiliario-Fii.Htm

Braido, G. M. (2014). Planejamento financeiro pessoal dos alunos do curso das áreas de gestão: estudo em uma instituição de ensino superior do rio Grande do Sul. Estudo e Debate. Lajeado, 21(1), 37-58 www.univates.br/revistas/index.php/estudoedebate.

Cerbasi, G. (2014). Adeus, aposentadoria. Como garantir seu futuro sem depender dos outros. Sextante.

Cerbasi, G. (2013). Investimentos inteligentes. Sextante.

Cherobim, A. P. M. S., \& Espejo, M. M. dos S. B. (2010). Finaças pessoais conhecer para enriquecer! Atlas.

Confederação Nacional de Dirigentes Lojistas (2019, março). Seis a cada dez brasileiros não se preparam para aposentadoria, revela pesquisa CNDL/SPC Brasil e Banco Central. http:// http://site.cndl.org.br/seis-em-cada-dez-brasileiros-nao-se-preparam-para-aposentadoria-revela-pesquisa-cndlspc-brasil-ebanco-central/

Constituição da República $\quad$ Federativa do Brasil. $\quad(1988, \quad 5$ de $\quad$ Brasília. https://www2.senado.leg.br/bdsf/bitstream/handle/id/518231/CF88_Livro_EC91_2016.pdf

Dietrich, J. \& Braido; G. M. (2016, maio, agosto). Planejamento financeiro para a aposentadoria. Um estudo com os alunos do curso de especialização de uma instituição de ensino superior. Revista de Sociedade, contabilidade e gestão, 11(2), 29-52. https://revistas.ufrj.br/index.php/scg/article/view/13378/9200

Domingos, R. (2013). Sabedoria financeira: o milagre da multiplicação de recursos. Thomas Nelson Brasil.

Ferreira, A. B. de H. (2010). Dicionário da língua portuguesa (5a ed.) Positivo.

França, L., H. F. P. \& Soares; D. H. P. (2009). Preparação para aposentadoria como parte da educação ao longo da vida. Rev. Psicologia, ciência e profissão, 29 (4), 738-751. https://www.scielo.br/scielo.php?pid=S1414-98932009000400007\&script=sci_abstract\&tlng=pt

Fulgêncio, P. C. (2007). Glossário VadeMecum: administração pública, ciências contábeis, direito, economia, meio ambiente: 14.000 termos e definições . Mauad, 2007.

Garcia, A. C. D. (2005, abril). Planejamento financeiro pessoal: um estudo sobre a renda pós aposentadoria. [Dissertação de Mestrado, Universidade Federal do Rio Grande do Sul]. Lume Repositório Digital da Universidade Federal do Rio Grande do Sul. http://www.lume.ufrgs.br

Gil, A. C. (2007). Métodos e técnicas de pesquisa social (5a ed.). Atlas.

Gil, A. C. (2016). Como elaborar projetos de pesquisa (5a ed.). Atlas.

Gitman, L. J. \& Joehnk, M. D. (2005). Princípios de investimentos (Trad. Maria Lucia Leite Rosa) (8a ed.). Pearson Universidades.

Hoji, M. (2011). Finanças da família: o caminho para a independência financeira (3a ed.). Companhia dos Livros

Goeking, W. (2018, 6 junho). Brasileiros deixam 2,4 bilhoes no pior investimento. Infomoney. https://www.infomoney.com.br/onde-investir/brasileirosdeixam-24-bilhoes-no-pior-investimento-do-ano-entenda/

Gonzalez, A. (2018, 25 julho). Pesquisa mostra que 76\% não praticam consumo consciente no Brasil. Globo Comunicação e Participações S.A, 25 jul. 2018. https://g1.globo.com/natureza/blog/amelia-gonzalez/post/2018/07/25/pesquisa-mostra-que-76-nao-praticam-consumo-consciente-no-brasil.ghtml

Instituto Brasileiro de Geografia e Estatística (2010). Censo 2010. www.ibge.gov.br/

Lizote, S. A., Simas, J. de, Verdinelli, M. A. \& Lana, J. (2016, setembro, dezembro). Finanças pessoais: um estudo envolvendo os alunos de ciências contábeis de uma instituição de esnsino superior da Santa Catarina. Revista da UNIFEBE, 1(19), 72-85. https://periodicos.unifebe.edu.br/index.php/revistaeletronicadaunifebe/article/download/186/373

Macedo Júnior, J. S. (2013). Árvore do dinheiro - guia para cultivar a sua independência financeira. Insular.

Mallmann, G. C. (2004). Estudo sobre a previdência social e sua influência na decisão de aderir a planos de previdência complementar aberta [Dissertação de Mestrado, Universidade Federal do Rio Grande do Sul]. Lume Repositório Digital da Universidade Federal do Rio Grande do Sul. http://hdl.handle.net10183/5352.

Martins, G. A. (2006). Estatística geral e aplicada (3a. ed.). Atlas. 
Research, Society and Development, v. 10, n. 1, e184910111638, 2021

(CC BY 4.0) | ISSN 2525-3409 | DOI: http://dx.doi.org/10.33448/rsd-v10i1.11638

Marques, M. S; Monteiro, S. C. M. \& Freitas, V. H. C. (2014). Previdência privada. Revista JusBrasil, https://stefanocmm.jusbrasil.com.br/artigos/147837252/previdencia-privada

Megliori, E. Vallin, M. A. (2009). Administração financeira: uma abordagem brasileira. Pearson Pretice Hall.

Mineghetti, N. A., Falceta, P. F., Rassier, H. L. \& Marchionatti, W. (2017). Educação financeira. PUCRS.

Neder, H. D. Amostragem em pesquisa sócio-econômicas. Alínea, 2008.

Nolasco, L. (2012, $\quad$ outubro). Aposentadoria $\quad$ especial. $\quad$ Âmbito $\quad$ Jurídico, $\quad$ n. $105 . \quad$ http://www.ambitojuridico.com.br/site/?n_link=revista_artigos_leitura\&artigo_id=12279

Organização para a Cooperação e Desenvolvimento Econômico e Comissão de Valores Mobiliários (2005) Recomendação sobre os princípios e as boas práticas de educação $\quad e \quad$ conscientização $\quad$ financeira. $\quad$ https://www.oecd.org/daf/fin/financialeducation/[PT]\%20Recomenda\%C3\%A7\%C3\%A3o\%20Princ\%C3\%ADpios\%20de\%20Educa\%C3\%A7\%C3\%A3o\%20Financeira\%202005\%20.pdf

Pereira, J. M. (2012). Manual de metodologia da pesquisa científica (3a. ed.) Atlas.

Portal do Investidor (2020). Títulos Públicos. https://www.investidor.gov.br/menu/Menu_Investidor/Old/Valores_Mobiliarios/Titulos_publicos.html

Secretaria Especial de Previdência e Trabalho (2020). O que é Previdência Complementar. https://www.gov.br/previdencia/pt-br/assuntos/previdenciacomplementar/mais-informacoes/o-que-previdncia-complementar

Segundo Filho, J. (2003). Finanças pessoais: invista no seu futuro. Qualitymark.

Santos, J. C. (2019). Previdência privada: o que é e como funciona? https://www.serasaconsumidor.com.br/ensina/dicas/previdencia-privada-o-que/

Superintendência de Seguros privados (2020, agosto). Previdência Complementar Aberta. http://www.susep.gov.br/menu/informacoes-ao-publico/planos-eprodutos/previdencia-complementar-aberta

Torres, F. C. D. (2012, março). Seguridade social: conceito constitucional e aspectos gerais. Âmbito Jurídico, Rio Grande, XV, 98. http://www.ambitojuridico.com.br/site/index.php?n_link=revista_artigos_leitura\&artigo_id=11212

Wisniewski, M. L. G. (2010). Gestão das finanças pessoais, uma ênfase na popularização do mercado de capitais brasileiro. Revista Insaberes. Curitiba, A. 6, (12), 155-172. 